\title{
Sorção de óleo diesel a partir da reutilização de garrafas PET
}

\section{Sorption of diesel oil from reusing of pet bottles}

\author{
1 Marina Jardim Faria de Araujo marina_jfa@hotmail.com \\ 2 Daniella Regina Mullinari \\ 3 Marcus Vinicius Faria de Araujo
}

1 Discente do curso de Engenharia Ambiental, UniFOA.
2 Docente da Universidade do Estado do Rio de janeiro, UERJ.

\section{Resumo}

A produção, transporte e o armazenamento de óleo diesel geram grande preocupação ambiental, econômica e social devido aos impactos gerados por esse derivado do petróleo na biota, no solo e na qualidade de vida humana em casos de derramamento. Muitas são as técnicas de controle usadas em áreas contaminadas pelo óleo diesel. Uma das técnicas atualmente utilizadas é a adsorção a partir do uso de polímeros. Sendo o polietileno tereftalato, mais conhecido como PET, um dos polímeros mundialmente mais utilizados e descartados após sua utilização, o presente trabalho vem aplicar o reuso de garrafas PET como alternativa de material adsorvente em ocorrências de vazamento de óleo diesel. Os testes de sorção foram realizados com flakes de PET em duas granulometrias (4 e 9 mesh) e em seis intervalos de tempo de sorção. A quantidade de óleo diesel sorvido pelos flakes de garrafas PET foi analisada por testes de sorção na ausência de água. Os resultados obtidos demonstraram que o PET pode ser considerado um bom sorvente e que a granulometria influenciou diretamente na capacidade de sorção do óleo. Foi possível inferir que as garrafas PET possuem potencial para combate a derramamentos de óleo diesel atenuando impactos ambientais em tais situações.

\section{Palavras-chave}

Óleo diesel; Polímeros; Adsorção.

\begin{abstract}
The production, transportation and diesel fuel storage generate major environmental, economic and social concern due to the impact generated by this derived from petroleum in the biota, soil and quality of human life in the event of spillage. There are many control techniques used in contaminated areas by diesel oil. One of the techniques currently used is adsorption by using polymers. Considering that the polyethylene terephthalate, known as PET, is one of the world's most used polymers and is discarded after its use, this paper aims to apply the reuse of PET bottles as an alternative adsorbent material in diesel oil spill occurrences. The sorption tests were carried out with PET flakes in two particle sizes (mesh 4 and 9) and six time intervals for sorption. The amount of diesel oil sorbed by flakes of PET bottles was analyzed by sorption tests in the absence of water. The results demonstrated that PET can be considered a good sorbent and that particle size directly influenced the oil sorption capacity. It was possible to infer that the PET bottles have the potential to combat diesel oil spills mitigating environmental impacts in such situations.
\end{abstract}

\section{Keywords}

Diesel oil; Polymers; Adsorption.

\section{Como você deve citar?}

ARAUJO, Marina Jardim Faria de; MULLINARI, Daniella Regina; ARAUJO, Marcus Vinicius Faria de. Sorção de óleo diesel a partir da reutilização de garrafas PET. Cadernos UniFOA, Volta Redonda, n. 29, p. 21-31, dez. 2015. 


\section{INTRODUÇÃO}

O petróleo representa hoje uma fonte essencial para obtenção de energia e matéria-prima para polímeros sintéticos. Ao longo da exploração, transporte ou armazenamento do petróleo e de seus derivados, tais como o óleo diesel, derramamentos são de suscetível ocorrência, podendo levar a danos ambientais em cadeia por meio da contaminação dos corpos hídricos e do solo.

A Agência Nacional do Petróleo (ANP) define o óleo diesel como: "Fração do petróleo composta principalmente por hidrocarbonetos alifáticos". 0 óleo diesel é ligeiramente mais denso do que o querosene e destila na faixa entre 250 e $400^{\circ} \mathrm{C}$. Este derivado do petróleo é bastante usado como combustível em motores de combustão interna, com alta compressão e combustão instantânea (ANP, 2011). No Brasil, o consumo de diesel automotivo se restringe basicamente ao setor agrícola e de transporte rodoviário.

Acidentes com óleo diesel no ambiente constituem um evento comum e, muitas vezes, uma ocorrência de grandes proporções (GAO et al., 2000). O óleo diesel não é apenas fisicamente prejudicial para o ambiente, mas também quimicamente prejudicial, porque contém muitos compostos tóxicos em concentrações relativamente grandes (SALANITRO et al., 1997).

Existe um número elevado de postos revendedores de combustíveis no Brasil no cenário atual. Segundo o Instituto Estadual do Meio Ambiente (INEA), hoje, no estado do Rio de Janeiro, existem cerca de 2500 postos de serviços revendedores de óleo diesel licenciados.

De acordo com o Oliveira (2010), o número de grandes vazamentos (maior do que 700 toneladas) tem diminuído nos últimos trinta anos, e a maioria dos acidentes é de médio ou pequeno porte (OLIVEIRA, 2010), mas considerando que médio a pequeno porte são quantidades de 7 a 700 toneladas, os impactos ambientais criados são bastante expressivos.

Contudo, o lançamento de efluentes oleosos vindos de cozinhas e indústrias em geral em corpos d'água, além dos óleos provenientes do setor petroleiro e seus derivados como o óleo diesel, são também responsáveis pela contaminação do meio (SRINIVASAN; VIRARAGHAVAN, 2008).

\footnotetext{
Devido à formação de filmes, a poluição oriunda do derramamento de petróleo e derivados compromete a economia, a vida marinha, o lazer e o turismo em áreas afetadas. 0 crescimento excessivo de algas verdes altera a cor do mar afetando a beleza da paisagem, sem contar com o forte cheiro de óleo que pode ser percebido a quilômetros de distância. Em rios, os poluentes são levados pela correnteza causando grandes prejuízos. Em mar aberto e em portos as correntes agravam as consequências da poluição instalada (BUCAS; SALIOT, 2002, p. 1390).
}

Existem muitas medidas atualmente utilizadas para mitigação dos impactos ambientais gerados por um possível vazamento de derivados do petróleo. Dentre os métodos convencionais, segundo Srinivasan e Viraraghavan (2010), pode-se citar a separação por gravimetria, dissolução por flotação, coalescência, centrifugação, floculação e coagulação. No entanto, esses métodos podem muitas vezes não remover o óleo efetivamente, ou mesmo causam alterações nas características do óleo derramado.

Em vista da certa ineficiência dos métodos convencionais, é fundamental que a busca por materiais sorventes alternativos que auxiliem na remoção de óleos em situações de derramamento seja estudada e aplicada.

Materiais sorventes (do latim "sorbere") são definidos por Annuciado (2005) como materiais que têm a capacidade de se encharcar de líquido. Segundo o autor, a sorção pode ser nomeada como adsorção e/ou a absorção, podendo estas atuar separadamente ou em conjunto. 
Absorventes são materiais em que o óleo penetra nos poros da sua estrutura. Adsorventes atraem o óleo para sua superfície, mas não permitem que penetre no seu interior (ANNUNCIADO, 2005).

Moreira (2004) destaca que a adsorção é o termo utilizado para descrever o fenômeno no qual moléculas que estão presentes em um fluido, líquido ou gasoso, concentram-se espontaneamente sobre uma superfície sólida. Geralmente, a adsorção parece ocorrer como um resultado de forças não balanceadas na superfície do sólido e que atraem as moléculas de um fluido em contato por um tempo finito.

A hidrofobicidade e a oleofilicidade são os fatores primários determinantes do sucesso dos sorventes. Outros fatores importantes incluem a retenção de óleo por longo período de tempo, quantidade de óleo sorvido por unidade de peso do sorvente e a reutilização e biodegradabilidade do sorvente (TEAS et al., 2001, p. 261).

Moreira (2004) ressalta que a adsorção está intrinsecamente ligada à tensão superficial das soluções e a intensidade disto é dependente da temperatura, da natureza e a concentração da substância adsorvida bem como da natureza, potencial de agregação do adsorvente e do fluido em contato com o adsorvente.

Considerando-se que a tensão superficial é um fenômeno de superfície, pode-se dizer que quanto maior a presença de soluto na superfície da solução, menor a tensão superficial da solução e mais facilmente o soluto será adsorvido pelo sólido (DELIYANNI et al., 2007).

Segundo Rajakovic-Ognjanovic et al. (2008), a sorção, no estágio de tratamento de água poderia ser eficiente, não somente para a remoção de óleo, mas também, para remover todas as substâncias que possuem afınidade física (adsorção) ou química (quimisorção) por influência dos grupos ativos presentes nos sorventes.

Para um material ser considerado um bom sorvente, deverá apresentar elevada capacidade de sorção, a qual depende de fatores como: área superficial, tipos de superfície (porosa, oleofílica ou polar) (FERREIRA, 2009).

Os sorventes podem ser classificados em sintéticos ou naturais. Sorventes sintéticos como os poliuretanos e polietilenos, segundo Tanobe (2007) e Lin (2012), apesar de possuírem custo relativamente alto de obtenção e baixas taxas de degradabilidade, possuem vantagens em processos de limpeza em derramamentos de petróleo e derivados, pois chega a absorver até 70 vezes o seu peso em óleo.

Plásticos ou polímeros sintéticos têm se tornado uma das maiores problemáticas dos resíduos sólidos urbanos devido ao crescente cenário consumista, que gera quantidades significativas quando se trata do aumento do volume de lixo disposto em aterros e a poluição visual. Em contrapartida, a reutilização e a reciclagem de plásticos têm minimizado problemas ambientais diversos por meio do desenvolvimento de novos artefatos e de novas aplicações.

Polímeros orgânicos porosos são largamente utilizados nas tecnologias de sorção modernas. Uma das vantagens das macromoléculas quando comparados aos sorventes minerais é a possibilidade de ajuste da estrutura geométrica e dos seus poros (WEl et al., 2003; FARIN; AVNIR, 1989). 
No Brasil, a principal aplicação do PET é na indústria de embalagens (71\%). Conforme destacado por Romao, Spinacé e De Paoli (2009), o segmento do mercado nacional da indústria alimentícia e embalagens corresponde a $32 \%$ do mercado brasileiro de polímeros envolvendo o uso do PET para embalagens de bebidas.

Segundo o estudo, os polímeros têm aumentado sua participação na composição dos resíduos sólidos urbanos (RSU) nos últimos anos. A partir do ano de 2005, eles contribuíram com cerca de $20 \%$ (porcentagem em massa) dos RSU coletados no Brasil.

Devido à grande quantidade e variedade das aplicações dos polímeros e o seu tempo de degradação relativamente longo, eles são considerados os grandes vilões ambientais por ocuparem uma boa parte do volume dos aterros (SPINACÉ; DE PAOLI, 2005).

No entanto, os problemas ambientais não são causados pelos polímeros, e sim pelo seu descarte de forma inadequada. A utilização dos polímeros como o PET na sorção de óleos derivados do petróleo tal como o diesel pode ser a solução para minimizar esse impacto ambiental.

Considerando que o Polietileno tereftalato ocupa espaço expressivo ao ser descartado e sendo este um polímero potencialmente adsorvente, o objetivo deste trabalho foi propor a adsorção do óleo diesel reutilizando como material polimérico adsorvente o PET.

\section{MÉTODOS E TÉCNICAS}

Os métodos e procedimentos adotados para atingir os objetivos propostos foram realizados no intuito de obter as informações necessárias para definir a capacidade de sorção dos flakes obtidos a partir da reciclagem de garrafas plásticas. 0 óleo diesel utilizado em todos os ensaios de sorção foi obtido em posto revendedor PETROBRAS no município de Volta Redonda - RJ e é comercialmente denominado $\$ 1800$.

\subsection{Obtenção dos flakes}

Para a confecção do material adsorvente (flakes) foram utilizadas garrafas plásticas verdes feitas de Poli (tereftalato de etileno)- PET. Após a seleção das garrafas plásticas, essas foram lavadas com água deionizada, secas em estufa por 12 horas a $80^{\circ} \mathrm{C}$ e trituradas no liquidificador industrial (JBM 43).

\subsection{Avaliação dos flakes}

\subsubsection{Avaliação granulométrica}

Os flakes foram submetidos à separação granulométrica utilizando a técnica de peneiramento. As granulometrias utilizadas no presente trabalho foram a de 4 e 9 mesh.

A separação por granulometria pode ser justificada pelo fato de que, ao se reduzir o tamanho da partícula, a área superficial e a área de contato entre elas aumentam, acarretando uma melhor adsorção.

No entanto, se a granulometria for muito pequena pode haver empacotamento, devido à presença de cargas eletrostáticas, o que dificultará a sorção de óleo (BITTENCOURT et al., 2009).

A Figura 1 a seguir mostra o material obtido da separação granulométrica dos flakes com 4 mesh. 
Figura 1 - Flakes de 4 mesh após separação de granulometria das garrafas plásticas trituradas.

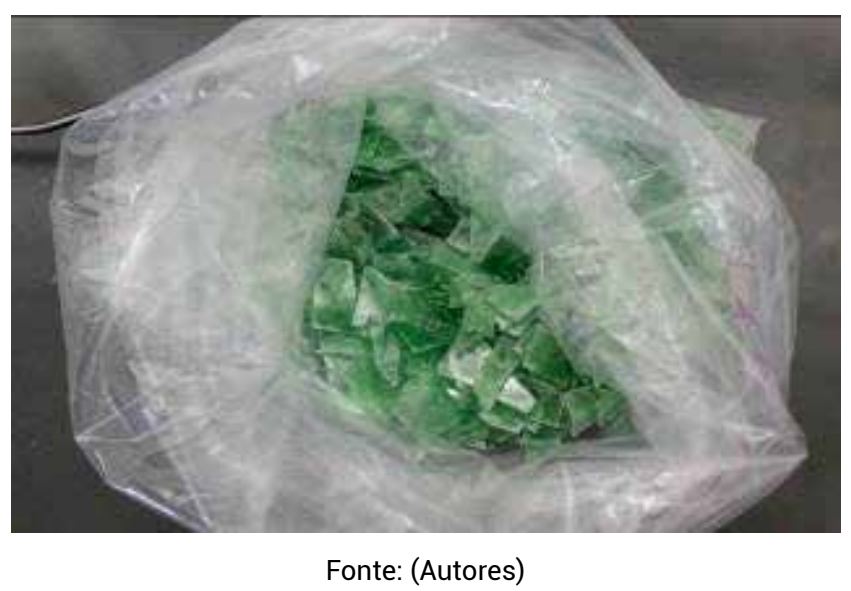

\subsection{Análise morfológica dos flakes}

Os flakes foram analisados em um Microscópio Eletrônico de Varredura (MEV), disponível no Laboratório de Materiais do Centro Universitário de Volta Redonda, operando de 15 a 20 kW e utilizando detector de elétrons secundários.

As amostras foram depositadas sobre suportes metálicos, utilizando adesivos condutores, como fita de carbono, devido a não condutibilidade da maioria dos polímeros. O revestimento da amostra é feito por um filme condutor que teve como finalidade evitar o acúmulo de carga negativa, para o caso de material não condutivo.

\section{DESENVOLVIMENTO / EXPERIMENTAL}

Nos ensaios de sorção de diesel a partir de flakes de PET com 4 e 9 mesh, foram colocados em um béquer, com $20 \mathrm{~mL}$ de óleo diesel, 0,500 gramas do material adsorvente, tanto para o de 4 mesh quanto para o de 9 mesh, objetivando adsorção nos intervalos de tempo de 10, 20, 30, 40, 50 e 60 minutos.

Após o período de sorção, o conteúdo de cada béquer foi drenado por 10 minutos. Após essa etapa, o material sorvente contido na peneira foi pesado em balança de precisão a fim de determinar o percentual de óleo diesel adsorvido (capacidade de adsorção do material) e fazer análises de comportamento do material ao longo do tempo de sorção bem como de comparação entre as granulometrias da garrafa PET utilizadas. A capacidade de adsorção do material foi calculada a partir da Equação 1 a seguir:

$C_{s}=\frac{M_{f}-M_{i}}{M_{i}} \times 100 C_{s}=\frac{M_{f}-M_{i}}{M_{i}} \times 100$

onde CS é a capacidade de sorção do óleo, $\mathrm{M}_{\mathrm{i}}$ e $\mathrm{M}_{\mathrm{f}}$ correspondem as massas das amostras antes e após a imersão em óleo.

A Figura 2 a seguir mostra os ensaios de sorção de óleo diesel com flakes de garrafas PET de 10 e 60 minutos de sorção. 
Figura 2 - Ensaio de Sorção de Óleo Diesel com flakes de PET em 10 e 60 minutos.
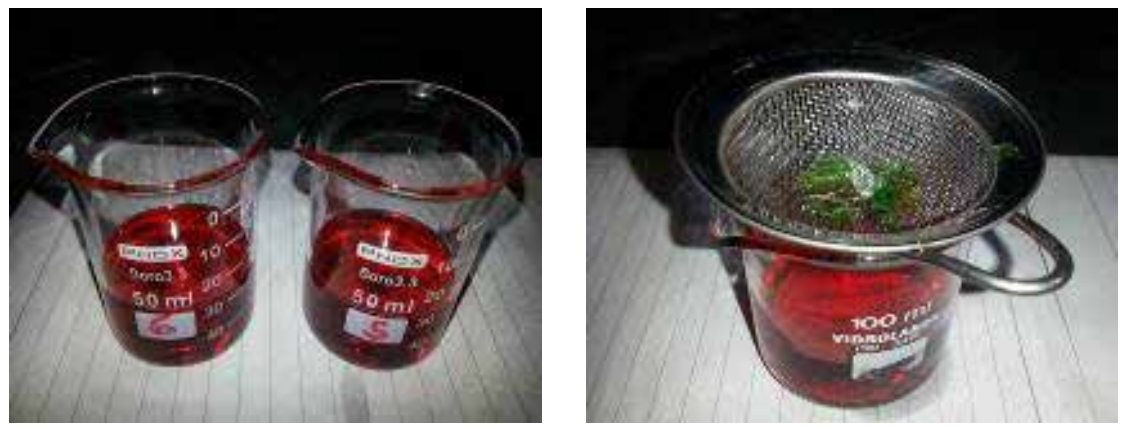

Fonte: (Autores)

\section{RESULTADOS E DISCUSSÃO}

\subsection{Capacidade de sorção de óleo Diesel}

A partir dos ensaios de sorção de óleo diesel a partir dos flakes de PET de 4 e 9 mesh, foram obtidos resultados da massa dos flakes após os 10 minutos de drenagem. Por meio do conhecimento dos valores de massa inicial e massa final em cada ensaio, foi calculada a capacidade de sorção do material polimérico a fim de elaborar comparações de eficiência de sorção entre granulometrias e entre tempo de contato com o óleo.

Dessa forma, foi elaborada a Tabela 1, a seguir, em que se têm os percentuais da quantidade sorvida de óleo diesel pelos flakes de 4 e 9 mesh nos intervalos de tempo de 10, 20, 30, 40, 50 e 60 minutos.

Tabela 1 - Média dos Resultados Analíticos obtidos nos ensaios de sorção com flakes de 4 mesh e 9 mesh.

\begin{tabular}{ccccccc}
\hline $\begin{array}{c}\text { Amostra } \\
\text { (4 mesh) }\end{array}$ & Mi & Mf & Tempo (min) & \% de Diesel Sorvido & Cs (g/g) & Desvio Padrão (\%) \\
\hline 1 & 0,5085 & 0,8211 & 10 & $61,51 \%$ & $0,6151 \pm 0,08$ & $8,49 \%$ \\
\hline 2 & 0,5022 & 0,8077 & 20 & $60,78 \%$ & $0,6078 \pm 0,04$ & $4,20 \%$ \\
\hline 3 & 0,5061 & 0,8175 & 30 & $61,49 \%$ & $0,6149 \pm 0,09$ & $8,96 \%$ \\
\hline 4 & 0,5059 & 0,7924 & 40 & $56,61 \%$ & $0,5661 \pm 0,03$ & $3,22 \%$ \\
\hline 5 & 0,5064 & 0,8335 & 50 & $64,56 \%$ & $0,6456 \pm 0,04$ & $4,00 \%$ \\
\hline 6 & 0,5050 & 0,8262 & 60 & $63,52 \%$ & $0,6352 \pm 0,06$ & $6,20 \%$ \\
\hline $\begin{array}{c}\text { Amostra } \\
(9 \text { mesh) }\end{array}$ & Mi & Mf & Tempo (min) & $\%$ de Diesel Sorvido & Cs (g/g) & Desvio Padrão (\%) \\
\hline 1 & 0,5064 & 0,8153 & 10 & $60,98 \%$ & $0,6098 \pm 0,04$ & $4,47 \%$ \\
\hline 2 & 0,5032 & 0,7883 & 20 & $56,62 \%$ & $0,5662 \pm 0,03$ & $3,09 \%$ \\
\hline 3 & 0,5042 & 0,7880 & 30 & $56,26 \%$ & $0,5629 \pm 0,03$ & $3,64 \%$ \\
\hline 4 & 0,5067 & 0,7726 & 40 & $52,50 \%$ & $0,5250 \pm 0,05$ & $4,91 \%$ \\
\hline 5 & 0,5053 & 0,8063 & 50 & $58,53 \%$ & $0,5853 \pm 0,13$ & $12,69 \%$ \\
\hline 6 & 0,5063 & 0,7406 & 60 & $46,18 \%$ & $0,4618 \pm 0,13$ & $12,63 \%$ \\
\hline
\end{tabular}

Fonte: (Autores) 
A Figura 3 evidencia um gráfico de dispersão mostrando a correlação linear entre os dados e a variação da quantidade de óleo diesel sorvido em função do tempo de sorção para os flakes de 4 mesh.

Figura 3 - Média, Desvio Padrão e Correlação Linear dos ensaios de sorção com flakes de 4 mesh.

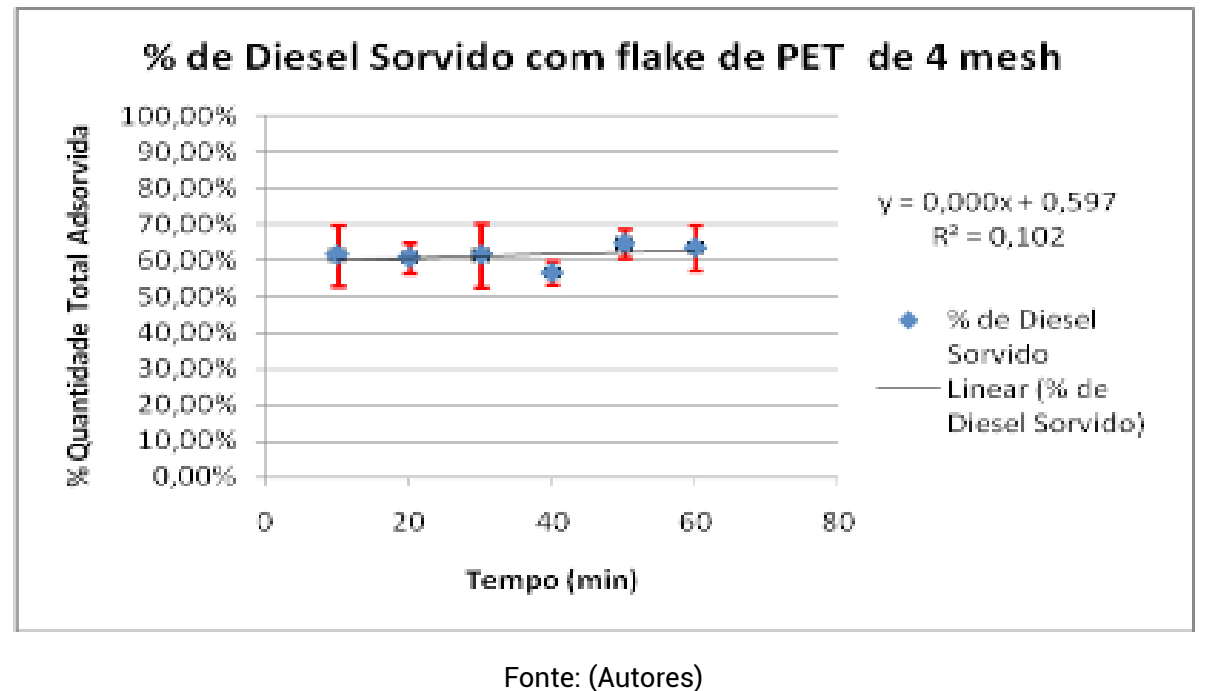

Analisando a Tabela 1 e a Figura 3 foi possível perceber que conforme o tempo de sorção aumenta ocorre um aumento da capacidade de sorção de óleo diesel a partir de flakes de garrafas plásticas. Foi observado também que a capacidade de sorção atingiu seu máximo, considerando os desvios, no tempo de 50 minutos, indicando que neste intervalo de tempo o material atingiu o máximo de acúmulo de óleo em seus poros, proporcionando máxima eficiência na capacidade de sorção do diesel. No entanto, os testes de 10 e 30 minutos apresentaram desvio padrão elevado, podendo também ser considerados intervalos de tempos de melhor performance na sorção de óleo diesel.

A Figura 4 a seguir mostra o gráfico de dispersão evidenciando a correlação linear entre os dados obtidos com flakes de 9 mesh e a variação da quantidade de óleo diesel sorvido em função do tempo de sorção.

Figura 4 - Média, Desvio Padrão e Correlação Linear dos ensaios de sorção com flakes de 9 mesh.

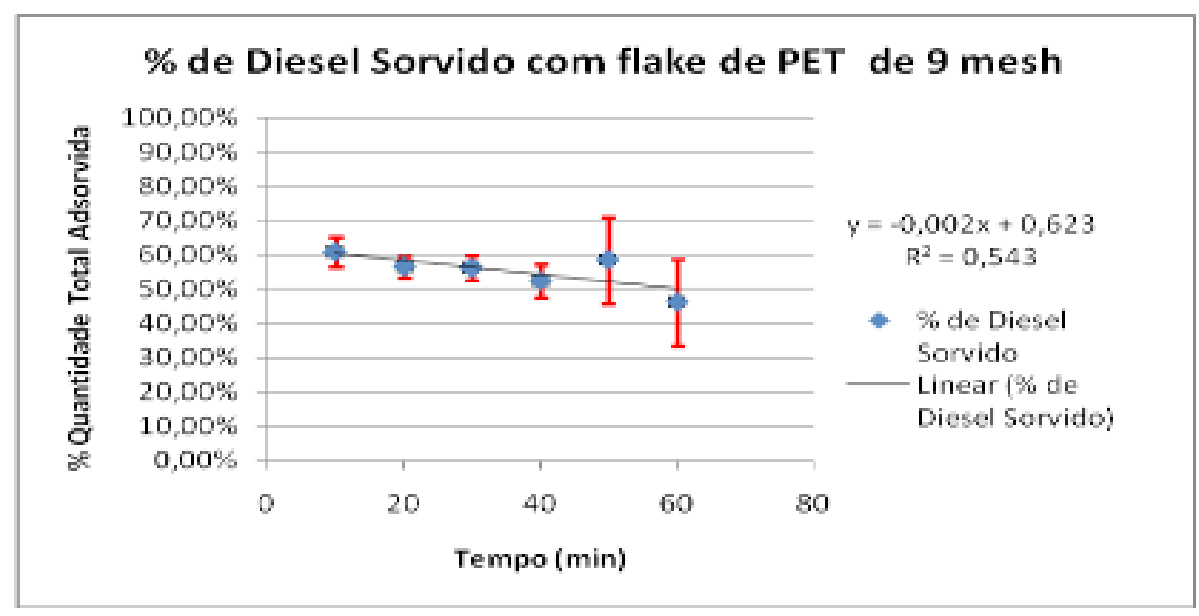

Fonte: (Autores) 
Na Tabela 1 e na Figura 4, é notável que, ao aumentar o tempo de sorção com flakes de 9 mesh, a capacidade deste material de sorver óleo diesel foi reduzida, ao contrário do que se observou nos ensaios com flakes de 4 mesh.

No entanto, o desvio padrão elevado para os intervalos de tempo de 50 e 60 minutos podem representar que nestes intervalos o material poderia ter apresentado capacidade de sorção maior que os outros tempos de sorção. Desconsiderando os erros, o tempo de sorção de 10 minutos foi o de meIhor desempenho na sorção; porém, considerando-os, o tempo de 50 minutos poderia ter apresentado maior capacidade de sorção para os flakes de 9 mesh.

Em se tratando de comparações entre os flakes de granulometria diferentes, pode-se perceber por meio de uma sobreposição dos gráficos representada na Figura 5 a seguir que, para os tempos de 10, 20, 30 e 40 minutos, os flakes de garrafa PET com 9 mesh obtiveram maior capacidade de adsorção quando comparado aos flakes de 4 mesh. Já nos tempos de 50 e 60 minutos, os flakes com 4 mesh obtiveram maiores desempenhos de sorção.

Figura 5 - Comparativo entre as médias dos resultados obtidos nos ensaios de sorção de óleo diesel com flakes de 4 e 9 mesh.

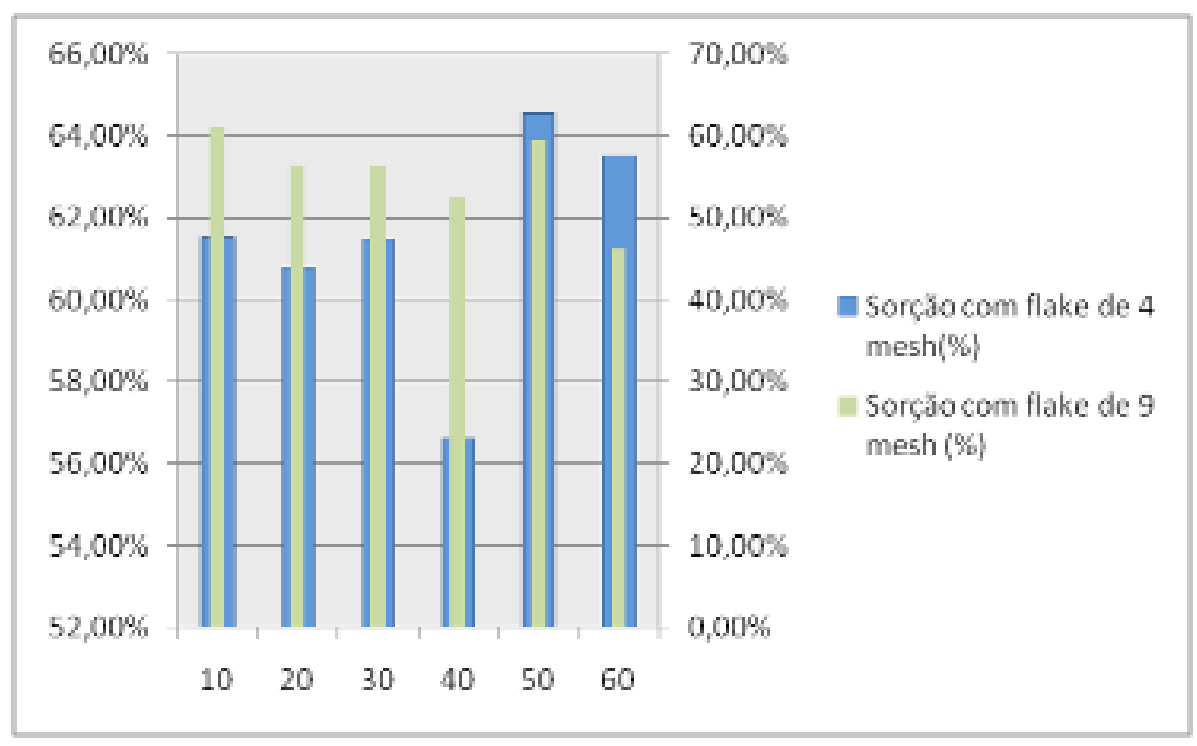

Fonte: (Autores)

Contudo, como citado previamente, os flakes de 9 mesh nos tempos de 50 e 60 minutos tiveram desvio padrão elevado, que se considerados para este comparativo, provavelmente possuiriam maior capacidade de sorção do que nos ensaios de 4 mesh.

\subsection{Morfologia dos flakes}

Na Figura 6 a seguir estão apresentadas uma das micrografias da amostra de PET triturada. 
Figura 6 - Micrografia da amostra de PET de 60x.

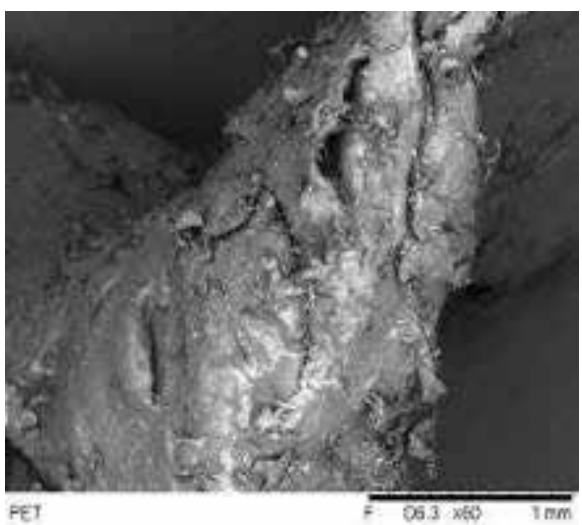

Fonte: (Autores)

Foi observado que as micrografias indicam que o PET apresentou fraturas justificadas pelo processo de trituração do material, permitindo formação de aberturas na amostra que podem ter contribuído na adsorção do diesel.

\section{CONCLUSÃo}

A partir dos resultados obtidos foi possível inferir que os flakes de garrafas PET são ótimos materiais sorventes para óleo diesel, pois para um material ser considerado um bom sorvente, deverá apresentar elevada capacidade de sorção (FERREIRA, 2009). Além disso, pode-se dizer que pela análise estatística dos resultados houve direta influência da granulometria na sorção do óleo diesel, já que os flakes de garrafas PET com 9 mesh se sobressaíram na capacidade de sorção em comparação aos flakes de 4 mesh nos dois casos.

Outra inferência obtida foi a de que os flakes de 4 e 9 mesh foram influenciados pelo tempo de sorção, fato que variou dependendo do tipo de óleo que estava sendo adsorvido. Desta forma, pode-se afirmar que este material poderá ser substituído pelos métodos convencionais no combate a vazamentos e/ou derramamentos de óleo diesel em sua produção, transporte ou armazenamento atenuando impactos ambientais em tais situações.

\section{AGRADECIMENTOS}

Os autores agradem ao Conselho Nacional de Desenvolvimento Científico e Tecnológico pelo suporte financeiro e ao Centro Universitário de Volta Redonda pela disponibilização de equipamentos. 


\section{REFERÊNCIAS}

ANDRADE, Sabina. Avaliação de polietileno reciclado carregado com fibra de palma para confecção de módulo. 2007. Dissertação (Mestrado em Engenharia Mecânica) - Universidade Federal do Pará, Pará, 2007.

ANNUNCIADO, T.; SYDENSTRICKER, T.; AMICO, S. Sorção de óleo cru e derivados do petróleo por diferentes fibras vegetais. Petro e Química, v. 278, p. 71-76, 2005. Disponível em: <http://www.ufrgs. br/lapol/sorcao_de_oleo.pdf>. Acesso em: 3 jun. 2015.

ANP (Agência Nacional de Petróleo, Gás Natural e Biocombustíveis). Boletim da Produção de Petróleo e Gás Natural. 1. ed. Rio de Janeiro: Superintendência de Desenvolvimento e Produção, 201 1.4. Disponível em: <www.anp.gov.br/?dw=59164>. Acesso em: 3 jun. 2015.

BUCAS, G.; SALIOT, A. Sea transport of animal and vegetable oils and its environmental consequences. Marine pollution bulletin, v. 44, n. 12, p. 1388-1396, 2002. Disponível em: <http://www.sciencedirect. com/science/article/pii/S0025326X0200303X>. Acesso em: 5 jun. 2015

DELIYANNI, E.; PELEKA, E.; LAZARIDIS, N. Comparative study of phosphates removal from aqueous solution by nanocrystalline akaganéite and hybrid surfactant-akaganéite. Separation and Purification Technology, v. 52, p. 478-486, 2007. Disponível em: <http://www.sciencedirect.com/science/article/pii/ S1383586606001936>. Acesso em: 17 jul. 2015.

FARIN, D.; AVNIR, D. The effects of fractal geometry of surfaces on the adsorption conformation of polymers at monolayer coverage. Part I. The case of polystyrene. Colloid and Surfaces, v. 37, p. 144170, 1989. Disponível em: <http://www.sciencedirect.com/science/article/pii/0166662289801155>. Acesso em: 3 ago. 2015.

FERREIRA, Tatiana. Sorção de petróleo por fibras naturais. 2009. Dissertação (Mestrado em Engenharia Mecânica) - Universidade Federal do Rio Grande do Norte, Natal, 2009.

GAO, B.; YANG, L.; WANG, X.; ZHAO, J.; SHENG, G. Influence of modified soils on the removal of diesel fuel oil from water and the growth of oil degradation micro-organism. Chemosphere, v. 41, p. 419-426, 2000. Disponível em: <http://www.sciencedirect.com/science/article/pii/S0045653599002878>. Acesso em: 6 ago. 2015.

LIN, J.; SHANG, Y.; DING, B.; YANG, J.; YU, J.; AL-DEYAB, S. Nanoporous polystyrene fibers for oil spill cleanup. Marine Pollution Bulletin, v. 64, p 347-352, 2012. Disponível em: <http://www.sciencedirect. com/science/article/pii/S0025326X11005790>. Acesso em: 17 jul. 2015.

MOREIRA, Cindy. Adsorção competitiva de Cádmio, Cobre, Níquel e Zinco em solos. 2004. Dissertação (Mestrado em Agronomia) - Universidade de São Paulo, Piracicaba, São Paulo, 2004.

OLIVEIRA, Adriana. Avaliação de desempenho de fibras lignocelulósicas na sorção de óleos diesel e biodiesel. 2010. Tese de Doutorado em Agronomia (Energia na Agricultura) - UNESP, Universidade Estadual Paulista, Botucatu, 2010.

RAJAKOVIC-OGNJANOVIC, V.; ALEKSIC, G.; RAJAKOVIC, L. Governing factors for motor oil removal from water with different sorption materials. Journal of Hazardous Materials, v. 154, p. 558-563, 2008. Disponível em: <http://www.researchgate.net/publication/5786916>. Acesso em: 5 jul. 2015. 
ROMÃO, W.; SPINACÉ, M. A. S.; DE PAOLI, M.. Poli (tereftalato de etileno), PET: Uma revisão sobre os processos de síntese, mecanismos de degradação e sua reciclagem. Polímeros: Ciência e Tecnologia, v. 19, n. 2, p. 121-132, 2009. Disponível em: <http://www.scielo.br/scielo.php?script=sci_arttext\&pid=S0104$14282009000200009 \&$ Ing=en\&nrm=iso >. Acesso em: 4 jul. 2015.

SALANITRO, J. et al. Crude oil hydrocarbon bioremediation and soil ecotoxicity assessment. Environmental and Science Technology, v. 31, p. 1769-1776, 1997. Disponível em: <http://pubs.acs.org/doi/pdf/10.1021/ es960793i . Acesso em: 17 ago. 2015.

SPINACÉ, M. S.; DE PAOLI, M. A tecnologia da reciclagem de polímeros. Química Nova, v. 28, n. 1, p. 6572, 2005. Disponível em: <http://quimicanova.sbq.org.br/imagebank/pdf/Vol28No1_65_13-RV03270. pdf>. Acesso em: 17 jul. 2015.

SRINIVASAN, A.; VIRARAGHAVAN, T. Removal of oil by walnut shell media. Bioresource Technology, v. 99, p. 8217-8220, 2008.

TEAS, C. et al. Investigation of the effectiveness of absorbent materials in oil spills clean up. Desalination, v. 140, n. 3, p. 259-264, 2001. Disponível em: <http://www.sciencedirect.com/science/article/pii/ S0011916401003757>. Acesso em: 20 ago. 2015.

WEI, Q. et al. Evaluation of Nowoven Polypropylene Oil Sorbents in Marine Oill-spill Recovery. Marine Pollution Bulletin, v. 46, p.783-870, 2003. Disponível em: <http://www.sciencedirect.com/science/article/ pii/S0025326X03000420>. Acesso em: 4 ago. 2015. 